\title{
Transient lupus anticoagulant and Fansidar therapy
}

\author{
R.F. Jeffrey \\ University Department of Clinical Pharmacology, The Royal Infirmary, Edinburgh, EH3 9YW, UK.
}

\begin{abstract}
Summary: A case of the Stevens-Johnson syndrome following Fansidar therapy is reported in which a marked feature was the presence of a circulating anticoagulant of the lupus inhibitor type. Treatment with steroids resulted in complete recovery and disappearance of the anticoagulant.
\end{abstract}

\section{Introduction}

Fansidar (sulfadoxine $500 \mathrm{mg}$ and pyrimethamine $25 \mathrm{mg}$ ) has been widely used for malarial prophylaxis, but it has recently been associated with severe side effects (Committee on Safety of Medicines, 1985).

\section{Case report}

A 33 year old American male was admitted whilst en route to Pakistan. He had awoken that morning with an intense headache and florid skin rash. Six days previously he had taken a single tablet of Fansidar and $300 \mathrm{mg}$ of chloroquine. He was not taking other drugs and there was no significant past medical history.

On examination he was ill with a fever of $40^{\circ} \mathrm{C}$. There was a widespread maculopapular rash with characteristic target lesions. He also had bilateral conjunctivitis, mouth ulceration, and widespread petechiae. Urine examination revealed microscopic haematuria. The white cell count was $23.9 \times 10^{9} / 1$. The platelet count was $183 \times 10^{9} / 1$ and remained normal throughout. The initial prothrombin ratio was abnormal at 1.2:1 and the activated partial thromboplastin time (APTT) prolonged at 61 seconds (control 42 seconds). The APTT was not corrected by the addition of an equal volume of normal plasma ( 53 seconds) and, on incubation, there was no change at 30 and 60 minutes. An infection screen, viral titres and hepatitis B surface antigen were negative. Antinuclear factor was not detected.

A diagnosis of Stevens-Johnson syndrome was made and treatment instituted with intravenous fluids, high dose prednisolone and antihistamines. He steadily improved over the next 5 days. The rash became continuous over the entire body surface before desquamating and the petechiae disappeared after a week. There was transient blood-stained diarrhoea

Correspondence: R.F. Jeffrey B.Sc., M.R.C.P.(UK)

Accepted: 8 April 1986 which settled spontaneously. His general improvement was associated with a steady fall in APTT towards normal within 3 days.

\section{Discussion}

The Stevens-Johnson syndrome is a well recognized complication of Fansidar therapy with a significant mortality. The most likely cause is the sulphonamide moiety, as this group has long been associated with erythema multiforme. It is of note that the patient also took chloroquine. It is possible that an interaction with chloroquine increases the frequency and severity of adverse reactions, and it has been suggested that the combined use of Fansidar and chloroquine is unwise in prophylaxis (World Health Organisation, 1985). In a recent review it has been stated that the StevensJohnson syndrome only occurs after multiple doses of Fansidar (Centers for Disease Control, Atlanta, 1985). There is no doubt that in this patient severe cutaneous reactions occurred after a single tablet.

A clotting defect due to the so-called 'lupus inhibitor' was first described in 1952 in systemic lupus erythematosis and, since then, it has been associated with a wide range of other conditions such as rheumatoid arthritis, lymphoma and carcinoma. In addition, it has been observed and suggested to have a pathogenic role in recurrent spontaneous abortions, pulmonary hypertension, transverse myelitis and neurological disease associated with systemic lupus erythematosis and Behçet's disease (Hughes, 1983). Appearance of the inhibitor has been associated with a number of drugs, such as penicillin and notably chlorpromazine, where therapy leads to the development of a number of immunological abnormalities (Zarrabi et al., 1979). There is no previous report of the lupus anticoagulant with Fansidar administration. It is an immunoglobulin of IgG or IgM which reacts with platelet wall phospholipid, suppressing the generation 
of prothrombin activator complex. In the laboratory it produces variable prolongation of the prothrombin time and consistent prolongation of the APTT without correction by normal plasma. In addition, the inhibition of APTT is instantaneous and without progression on incubation, features that differentiate it from the Factor VIII antibody which can occur in a similar range of conditions (Byron, 1982). The inhibitor found in the plasma of this patient satisfies these requirements. Bleeding is unusual, and, paradoxically, thromboembolic phenomena have been more commonly described, although the presence of the inhibitor often goes unnoticed clinically (Much et al., 1980). There is a strong correlation between the presence of the lupus anticoagulant and elevated titres of anticardiolipin antibody and the presence of either or both is associated with a high incidence of throm-

\section{References}

BRANCH, D.W., SCOTT, J.R., KOCHENOUR, N.K. \& HERSHGOLD, E. (1985). Obstetric complications associated with the lupus anticoagulant. New England Journal of Medicine, $313(21), 1322$.

BYRON, M.A. (1982). The clotting defect in SLE. Clinics in Rheumatic Diseases, 8, 137.

CENTERS FOR DISEASE CONTROL, ATLANTA. Morbidity and Mortality Weekly Report (Vol. 34, No. 14, 1985). Revised Recommendations for Preventing Malaria in Travellers to Areas with Chloroquine-resistant Plasmodium falciparum. Journal of the American Medical Association, 253, 2483.

COMMITTEE ON SAFETY OF MEDICINES (1985). Fansidar. Current Problems, 15, July. Market Towers, 1 Nine Elms Lane, London.

FENSTEIN, D.I. \& RAPAPORT, S.I. (1972). Acquired inhibitors of blood coagulation. Progress in Haemostasis and Thrombosis, 1, 75.

HARRIS, E.N., GHARAVI, A.E., BOEY, M.L., PATEL, B.M., bosis (Harris et al., 1983). Its relevance to the bleeding tendency seen here is uncertain. It is of interest that the inhibitor disappeared rapidly on steroid treatment and the use of steroids has been recommended when the lupus inhibitor is producing definite pathological changes (Fenstein \& Rapaport, 1972). Steroids in conjunction with aspirin appear to improve the outcome of pregnancy where the mother possesses the inhibitor, though the underlying disorder is not always corrected (Branch et al., 1985). In this man a fortuitous benefit of treatment of the primary condition was elimination of the circulating anticoagulant.

\section{Acknowledgements}

I would like to thank Dr G. Stockdill and Professor M.R. Lee for advice and guidance.
MACKWORTH-YOUNG, C.G., LOIZOV, S. \& HUGHES, G.R.V. (1983). Anticardiolipin antibodies: detection by radioimmunoassay and association with thrombosis in systemic lupus erythematosis. Lancet, ii, 1211.

HUGHES, G.R.V. (1983). Thrombosis, abortion, cerebral disease, and the lupus anticoagulant. British Medical Journal, 287, 1088.

MUCH, J.R., HERBST, K.D. \& RAPAPORT, S.I. (1980) Thrombosis in patients with the lupus anticoagulant. Annals of Internal Medicine, 92, 156.

WORLD HEALTH ORGANISATION (1985). Malaria chemoprophylaxis; problems associated with the chemoprophylaxis of malaria in travellers to endemic areas. Weekly Epidemiological Record, 14 June.

ZARRABI, M.H., ZUCKER, S., MILLER, F., DERMAN, R.M., ROMANO, G.S., HARTNETT, J.A. \& VARMA, A.O. (1979). Immunologic and coagulation disorders in chlorpromazine-treated patients. Annals of Internal Medicine, 91, 194. 